Journal of Advanced Research in Fluid Mechanics and Thermal Sciences

Journal homepage: www.akademiabaru.com/arfmts.html ISSN: 2289-7879

\title{
Unsteady Boundary Layer Flow Over a Permeable Stretching/Shrinking Cylinder Immersed in Nanofluid
}

\author{
Nor Fadhilah Dzulkifli ${ }^{1}$, Norfifah Bachok ${ }^{2}$, Nor Azizah Yacob $^{1,}{ }^{*}$, Norihan Arifin ${ }^{2}$, Haliza Rosali ${ }^{2}$, Ioan \\ Pop ${ }^{3}$ \\ Faculty of Computer and Mathematics Sciences, Universiti Teknologi MARA Pahang, Jengka Campus, Pahang, Malaysia \\ Department of Mathematics and Institute for Mathematical Research, Universiti Putra Malaysia, UPM, Serdang Selangor, Malaysia \\ Department of Mathematics, Babes-Bolyai University, Cluj-Napoca, 400084, Romania
}

\section{ARTICLE INFO}

\section{Article history:}

Received 26 April 2021

Received in revised form 30 June 2021

Accepted 8 July 2021

Available online 5 August 2021

\section{Keywords:}

Boundary Layer; Cylinder; Nanofluid; Stretching; Shrinking

\section{ABSTRACT}

In this study, the unsteady boundary layer flow over a stretching/shrinking cylinder immersed in copper (Cu)-water nanofluid with the presence of suction effect is analyzed. The governing partial differential equations are converted to ordinary differential equations using similarity transformation. The bvp4c solver in Matlab software is applied to solve the system of ordinary differential equations where the numerical solutions are obtained and presented graphically. The study aims to investigate the effects of nanoparticle volume fraction, the unsteadiness parameter, the stretching/shrinking parameter on the velocity and temperature gradients. It is found that the dual solutions are obtained in a specific range of these parameters for both stretching and shrinking cylinders. Besides, a high volume of the nanoparticles in the base fluid increases the velocity gradient and decreases the temperature gradient at the surface. Also, increasing nanoparticle volume fraction in the base fluid expands the range of solutions, which denotes the boundary layer separation from the surface has been delayed. The stability analysis is performed by introducing a new dimensionless variable to determine the stability of the solutions. In this phase, the smallest eigenvalue obtained shows that the first solution is stable and physically realizable while the second solution is not stable.

\section{Introduction}

The unsteady boundary layer problems have recently attracted the attention of many researchers where the considered parameters were depending on time; for example, Fang et al., [1] studied the expanding stretching cylinder in a viscous fluid where they identified that the Reynold number and the unsteadiness parameter controlled the fluid flow. The shrinking cylinder of the unsteady problem in viscous flow was proposed by Zaimi et al., [2] where the impact of mass suction and unsteadiness parameters on the velocity profile and velocity gradient has been analysed numerically. Marinca and Ene [3] solved a similar problem with Zaimi et al., [2] using an analytical method, namely the optimal

\footnotetext{
${ }^{*}$ Corresponding author.

E-mail address: norazizah872@uitm.edu.my
}

https://doi.org/10.37934/arfmts.85.2.2432 
homotopy asymptotic method (OHAM) to obtain the solutions. Their results showed a decent concurrence with the results generated numerically.

After that, Zaimi et al., [4] expanded their study by considering heat and mass transfer in nanofluid using Buongiorno's model, where the numerical solutions were obtained by the shooting method. They found that the unsteadiness parameter decreases the skin friction coefficient, local Nusselt number, and Sherwood number. Besides, the Brownian motion parameter also decreases both local Nusselt and Sherwood numbers, respectively. A similar nanofluid model had been used by Mahdy and Chamkha [5] in their study and besides, they considered non-Newtonian nanofluid. As a result, both the increasing unsteadiness parameter and Brownian motion decreased the heat and mass transfer rates at the surface.

Abbas et al., [6] extended the work by Zaimi et al., [4] by considering the partial slip condition of the flow over a porous stretching/shrinking cylinder. They presented the numerical solutions graphically and found that dual solutions exist for a shrinking surface. It was found that increasing the unsteadiness parameter decreases the magnitude of the skin friction coefficient but increases the temperature profile. A similar study had been considered by Azam et al., [7] in MHD Carreau nanofluid where the effect of thermal radiation is taken into account. They reported unique solutions exist and found that increasing the value of radiation parameters decreases the thermal boundary layer for dilatant and Pseudoplastic fluids. Further, Khan et al., [8] studied the effects of partial slip and suction parameters on the shrinking/stretching surface immersed in Williamson nanofluid. It was observed that the magnitude of skin friction coefficient decreases with increasing partial slip parameter while the heat and mass transfer rates at the surface increase. Further, by increasing suction parameters, all the magnitude of skin friction coefficient, heat and mass transfer rate are increased for the first solution.

Recently, Awaludin et al., [9] investigated the flow stability past a shrinking cylinder by considering prescribed surface heat flux as the boundary condition. They discovered that increasing the curvature parameter delays the boundary separation and dual solutions only obtained for a shrinking surface. A new class of unsteady flow was introduced by Fang [10], which flow over a long thin cylinder was considered and the end of the cylinder is either accretion or ablation. It was noted that for accretion, a unique solution was obtained, whereas dual solutions exist for ablation. Further, Yashkun et al., [11] studied the stagnation flow over a stretching/shrinking surface in Casson fluid with heat source and injection effect. They found dual solutions exist only for shrinking surface and a stability analysis was performed to determine the stability of solutions. Parvin et al., [12] analysed the stability of the solutions of MHD unsteady mixed convection flow towards an exponentially stretching/shrinking surface in Casson fluid and found that the first solution is stable whilst the second solution is not stable. Moreover, the most recent studies on the boundary layer flow over a cylinder can be found in [13-16].

In the present study, we extend the work of Abbas et al., [6] by investigating the flow and heat transfer characteristics of unsteady boundary layer flow towards a stretching/shrinking cylinder immersed in Cu-water nanofluid using a model introduced by Tiwari and Das [17]. The governing partial differential equations are transformed into a system of ordinary differential equations by applying similarity transformation using the appropriate similarity variables. The numerical solutions are obtained using a built-in bvp4c solver in Matlab and presented graphically. A stability analysis is performed since dual solutions are obtained to identify the stability of solutions. 


\section{Problem Formulation}

Consider an unsteady two-dimensional laminar flow past a permeable stretching/shrinking surface immersed in nanofluid as illustrated in Figure 1 . The fluid is assumed incompressible and the radius of the cylinder is a function of time with unsteady radius, $r=a(t)=a_{0} \sqrt{1-\beta t}$ where $a_{0}$ is a constant, $\beta$ is an expansion/contraction strength constant, and $t$ is a time. Let $u$ and $w$ represent the velocity component in $r$ and $z$ directions, respectively.

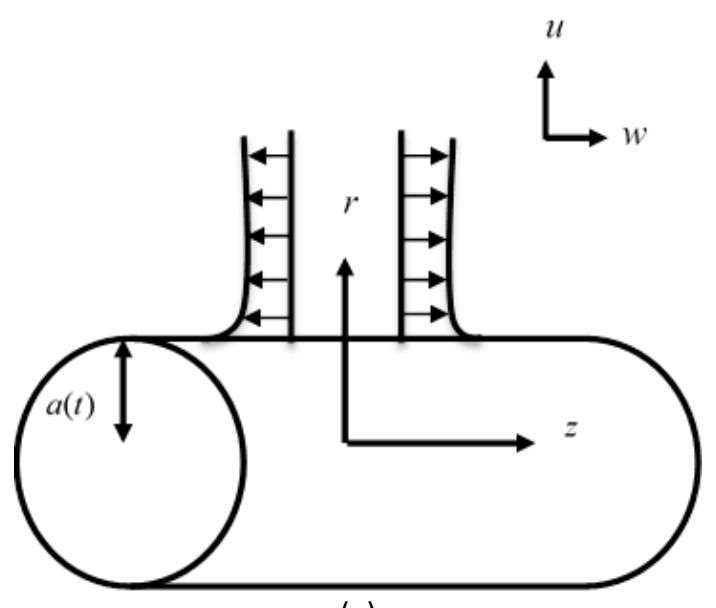

(a)

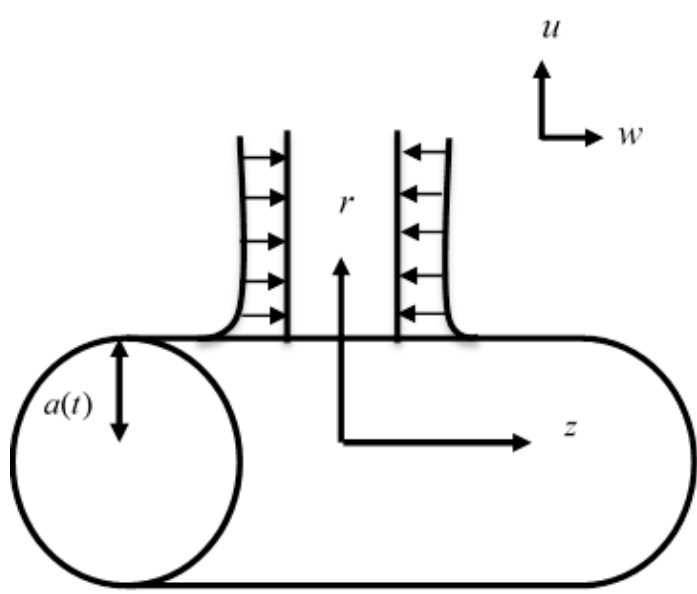

(b)

Fig. 1. Physical models and coordinate system; (a) stretching cylinder, (b) shrinking cylinder

Based on the assumptions above, Abbas et al., [6] and Tiwari and Das [17], the governing equations of the system can be written as follows

$\frac{1}{r} \frac{\partial(r u)}{d r}+\frac{\partial w}{\partial z}=0$

$\frac{\partial u}{\partial t}+u \frac{\partial u}{\partial r}+w \frac{\partial u}{\partial z}=-\frac{1}{\rho_{n f}} \frac{\partial p}{\partial r}+\frac{\mu_{n f}}{\rho_{n f}}\left(\frac{\partial^{2} u}{\partial r^{2}}+\frac{1}{r} \frac{\partial u}{\partial r}+\frac{\partial^{2} u}{\partial z^{2}}\right)$

$\frac{\partial w}{\partial t}+u \frac{\partial w}{\partial r}+w \frac{\partial w}{\partial z}=-\frac{1}{\rho_{n f}} \frac{\partial p}{\partial r}+\frac{\mu_{n f}}{\rho_{n f}}\left(\frac{\partial^{2} w}{\partial r^{2}}+\frac{1}{r} \frac{\partial w}{\partial r}+\frac{\partial^{2} w}{\partial z^{2}}\right)$

$\frac{\partial T}{\partial t}+u \frac{\partial T}{\partial r}+w \frac{\partial T}{\partial z}=\frac{k_{n f}}{\left(\rho c_{p}\right)_{n f}}\left(\frac{\partial^{2} T}{\partial r^{2}}+\frac{1}{r} \frac{\partial T}{\partial r}+\frac{\partial^{2} T}{\partial z^{2}}\right)$

subject to boundary conditions

$t<0: u=0, w=0, T=T_{\infty}$, for all $r$ and $z$,

$t \geq 0: u=w_{w}, w=U_{w}, T=T_{w}$ at $r=a(t)$,

$w \rightarrow 0, T \rightarrow T_{w}$ as $r \rightarrow \infty$,

where $z$ and $r$ are cylindrical polar coordinates measured in axial and radial directions, $p$ is the pressure of the nanofluid, $\rho_{n f}$ is the density of nanofluid, $\mu_{n f}$ is the dynamic viscosity of nanofluid, 
$T$ is the temperature of the nanofluid, $k_{n f}$ is the thermal conductivity of nanofluid, $\left(\rho c_{p}\right)_{n f}$ is the heat capacity of nanofluid and $U<0$ is the constant mass transfer (suction) and $U>0$ is the constant mass transfer (injection) velocities. The velocities in $r$ and $z$ directions and surface temperature $T_{w}$ are given by

$w_{w}=\frac{U}{\sqrt{1-\beta t}}, U_{w}=\frac{\varepsilon}{a_{0}} \frac{4 v_{f} z}{1-\beta t}, T_{w}=T_{\infty}+\frac{b z}{a_{0} v_{f}(1-\beta t)}$, where $b(>0)$ is a constant.

In order to transform the partial differential Eq. (1)-(4) to ordinary differential equations, we apply the related parameters as mentioned by Tiwari and Das [17] (for Eq. (5)-(8)) and introduce the following similarity transformation:

$u=-\frac{1}{a_{0}} \frac{2 v}{\sqrt{1-\beta t}} \frac{f(\eta)}{\sqrt{\mu}}, \quad w=\frac{1}{a_{0}^{2}} \frac{4 v z}{1-\beta t} f^{\prime}(\eta), \quad \eta=\left(\frac{r}{a_{0}}\right)^{2} \frac{1}{1-\beta t}, \quad \theta(\eta)=\frac{T-T_{\infty}}{T_{w}-T_{\infty}}$.

Substituting Eq. (6) and (7) into Eq. (1)-(5), then we obtain the following ordinary differential equations

$$
\begin{aligned}
& \chi\left(\eta f^{\prime \prime \prime}+f^{\prime \prime}\right)+f^{\prime \prime} f-f^{\prime 2}-A\left(\eta f^{\prime \prime}+f^{\prime}\right)=0 \text { where } \chi=1 /(1-\varphi)^{2.5}\left[1-\varphi+\varphi\left(\rho_{s} / \rho_{f}\right)\right], \\
& \frac{\zeta}{\operatorname{Pr}}\left(\eta \theta^{\prime \prime}+\theta^{\prime}\right)-\left[\theta f^{\prime}-f \theta^{\prime}+A\left(\eta \theta^{\prime}+\theta\right)\right]=0 \text { where } \zeta=k_{n f} / k_{f}\left[1-\varphi+\varphi\left(\left(\rho c_{p}\right)_{s} /\left(\rho c_{p}\right)_{f}\right)\right],
\end{aligned}
$$

subject to the boundary conditions

$$
\begin{aligned}
& f(\eta)=s, f^{\prime}(\eta)=\varepsilon, \theta(\eta)=1 \text { at } \eta=1, \\
& f^{\prime}(\eta) \rightarrow 0, \theta(\eta) \rightarrow 0 \text { as } \eta \rightarrow \infty,
\end{aligned}
$$

where primes denote the differentiation with respect to $\eta, s=-u a_{0} / 2 v>0$ is the mass suction parameter whereas $s=-u a_{0} / 2 v<0$ is the mass injection parameter. Further, $A=a_{0}^{2} \beta / 4 v$ is the unsteadiness parameter and $\varepsilon$ is the stretching/shrinking parameter where $\varepsilon<0$ for shrinking sheet $\varepsilon>0$ for stretching sheet, $\varphi$ is the Cu nanoparticle volume fraction, $\rho_{s}$ is the density of solid fraction, $\rho_{f}$ is the density of fluid, $\left(\rho c_{p}\right)_{s}$ is the heat capacity of solid fraction and $\left(\rho c_{p}\right)_{f}$ is the heat capacity of fluid.

The physical quantities of interest in this problem are the skin friction coefficients $C_{f}$ and Nusselt number $N u$, which can be defined as

$C_{f}=\frac{\tau_{w}}{\rho w_{w}^{2}}, \quad N u=\frac{a(t) q_{w}}{k_{f}\left(T_{w}-T_{\infty}\right)}$ where $\tau_{w}=\mu_{n f}\left(\frac{\partial w}{\partial r}\right)_{r=a(t)}$ and $q_{w}=k_{n f}\left(\frac{\partial T}{\partial r}\right)_{z=a(t)}$

Substituting (7) into (11), we obtain 


$$
C_{f}(z / r)=\frac{1}{(1-\varphi)^{2.5}} f^{\prime \prime}(1), N u=-2 \frac{k_{n f}}{k_{f}} \theta^{\prime}(1) .
$$

\section{Stability Analysis}

A stability analysis has been applied to determine which solution is more stable since dual solutions are obtained for this case. Based on Weidman et al., [18], a dimensionless time variable $\tau$ needs to be introduced then we have

$$
\begin{gathered}
\tau=\frac{4 r^{2}}{a_{0}^{4} \beta(1-\beta t)}, u=-\frac{2 v_{f}}{a_{0} \sqrt{1-\beta t}} \frac{f(\eta, \tau)}{\sqrt{\eta}}, w=\frac{4 v_{f} z}{a_{0}^{2}(1-\beta t)} \frac{\partial f}{\partial \eta}(\eta, \tau), \eta=\left(\frac{r}{a_{0}}\right)^{2} \frac{1}{1-\beta t}, \\
\theta(\eta, \tau)=\frac{T-T_{\infty}}{T_{w}-T_{\infty}} .
\end{gathered}
$$

Further, by doing a similar derivation as reported by Parvin et al., [12] and Ismail et al., [19], the linearized eigenvalue problem is obtained as follows:

$$
\begin{aligned}
& \chi\left(\eta F_{0}{ }^{\prime \prime}+F_{0}{ }^{\prime \prime}\right)+f_{0}{ }^{\prime \prime} F_{0}+F_{0}{ }^{\prime \prime} f_{0}-2 f_{0}{ }^{\prime} F_{0}{ }^{\prime}-A \eta F_{0}{ }^{\prime \prime}-A F_{0}{ }^{\prime}+\eta \gamma F_{0}{ }^{\prime}=0 \\
& \frac{\zeta}{\operatorname{Pr}}\left(\eta G_{0}{ }^{\prime \prime}+G_{0}{ }^{\prime}\right)+F_{0} \theta_{0}{ }^{\prime}+f_{0} G_{0}{ }^{\prime}-G_{0} f_{0}{ }^{\prime}-F_{0}{ }^{\prime} \theta_{0}-A \eta G_{0}{ }^{\prime}-A G_{0}+\eta \gamma G_{0}=0
\end{aligned}
$$

subject to boundary conditions,

$$
\begin{aligned}
& F_{0}(\eta)=0, F_{0}{ }^{\prime}(\eta)=0, G_{0}(\eta)=0 \text { at } \eta=1, \\
& F_{0}{ }^{\prime}(\eta) \rightarrow 0, G_{0}(\eta) \rightarrow 0 \text { as } \eta \rightarrow \infty
\end{aligned}
$$

\section{Results and Discussion}

The effects of $\mathrm{Cu}$ nanoparticle volume fraction, $\varphi$, unsteadiness parameter, $A$ and stretching/shrinking parameter, $\varepsilon$ when $\operatorname{Pr}=6.2$ on the velocity and temperature gradients were considered in this paper. By solving the ordinary differential Eq. (8) and Eq. (9) subject to boundary conditions (10) using bvp4c solver in Matlab, the numerical results obtained have been compared with Abbas et al., [6] for certain values as shown in Table 1, which shows a good agreement. The thermophysical properties of water and Cu nanoparticles considered in this study are as reported by Oztop and Abu-Nada [20]. Figure 2 and Figure 3 depict the velocity and temperature gradients for a few values of nanoparticle volume fraction, $\varphi$ and unsteadiness parameters, $A$ where it shows that dual solutions are obtained. Based on Figure 2 and Figure 3, dual solutions can be categorized as the first solution and the second solution where the dual solutions exist for negative values of $A$ in the range of $A<A_{c}$. Besides that, a unique solution can be found at $A=A_{c}$ and no solution for $A>A_{c}$. It is seen that the velocity gradient of the first solution is increasing due to the increase of $\varphi$ but the second solution shows the opposite results, as shown in Figure 2. However, increasing $\varphi$ decreases the temperature gradient for both solutions. 


\section{Table 1}

Various values of $f^{\prime \prime}(1)$ for different values of $A$ when $\varepsilon=-1$ and $s=0.1$

\begin{tabular}{lllll}
\hline A & Abbas et al., [6] & \multicolumn{3}{c}{ Present results } \\
\cline { 2 - 5 } & First solution & Second solution & First solution & Second solution \\
\hline-4.0 & 3.84077 & -24.88224 & 3.84077 & -24.88224 \\
-3.5 & 3.29909 & -17.47316 & 3.29909 & -17.47316 \\
-3.0 & 2.73978 & -11.45527 & 2.73978 & -11.45527 \\
-2.5 & 2.14665 & -6.71496 & 2.14665 & -6.71496 \\
-2 & 1.46820 & -3.10294 & 1.46820 & -3.10294 \\
\hline
\end{tabular}

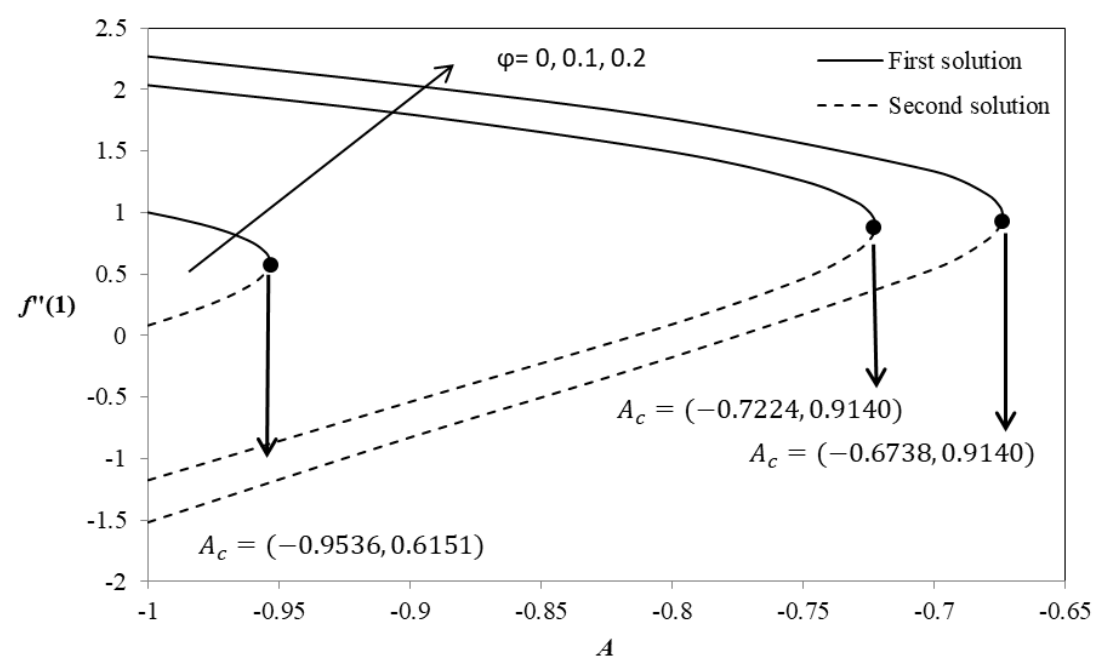

Fig. 2. Variations of $f^{\prime \prime}(1)$ with $A$ for different values of $\varphi$ when $s=1$ and $\varepsilon=-1$

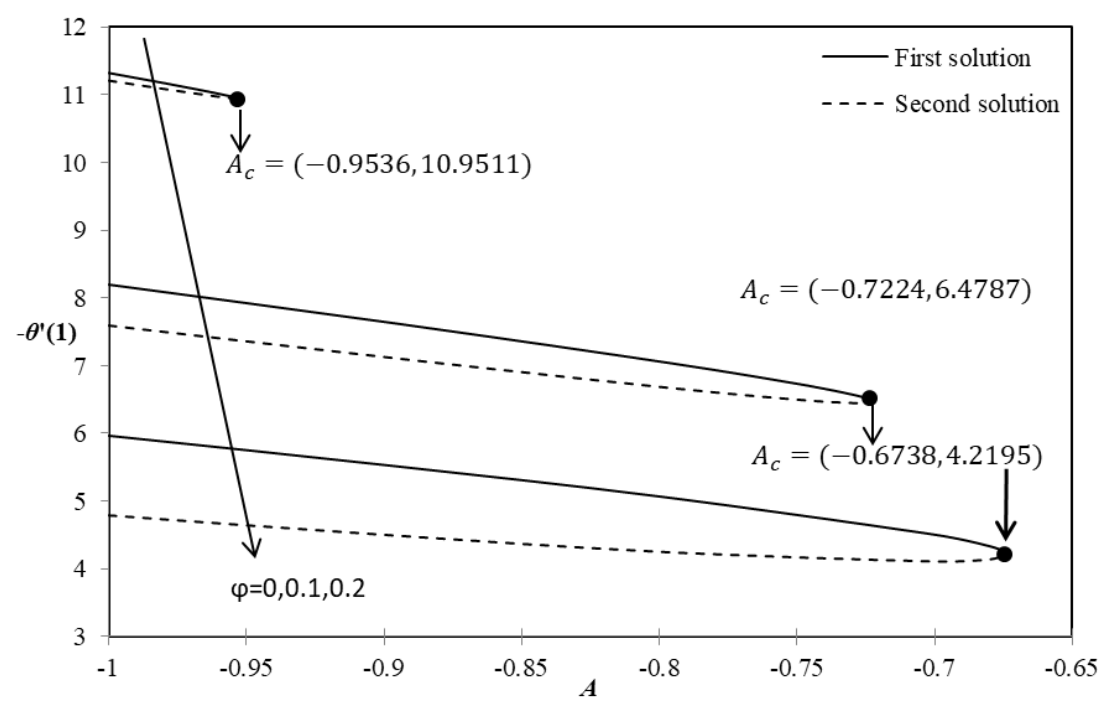

Fig. 3. Variations of $-\theta^{\prime}(1)$ with $A$ for different values of $\varphi$ when $s=1$ and $\varepsilon=-1$

The influence of $\mathrm{Cu}$ nanoparticles in the base fluid on the velocity gradient and temperature gradient with the effect of stretching/shrinking parameters are displayed in Figure 4 and Figure 5. Figure 4 proves that the existence of $\mathrm{Cu}$ nanoparticles in water increases the velocity gradient compared to the absence of $\mathrm{Cu}$ nanoparticles in the base fluid. Meanwhile, increasing $\varphi$ is seen to decrease the temperature gradient for both solutions as illustrated in Figure 5. 


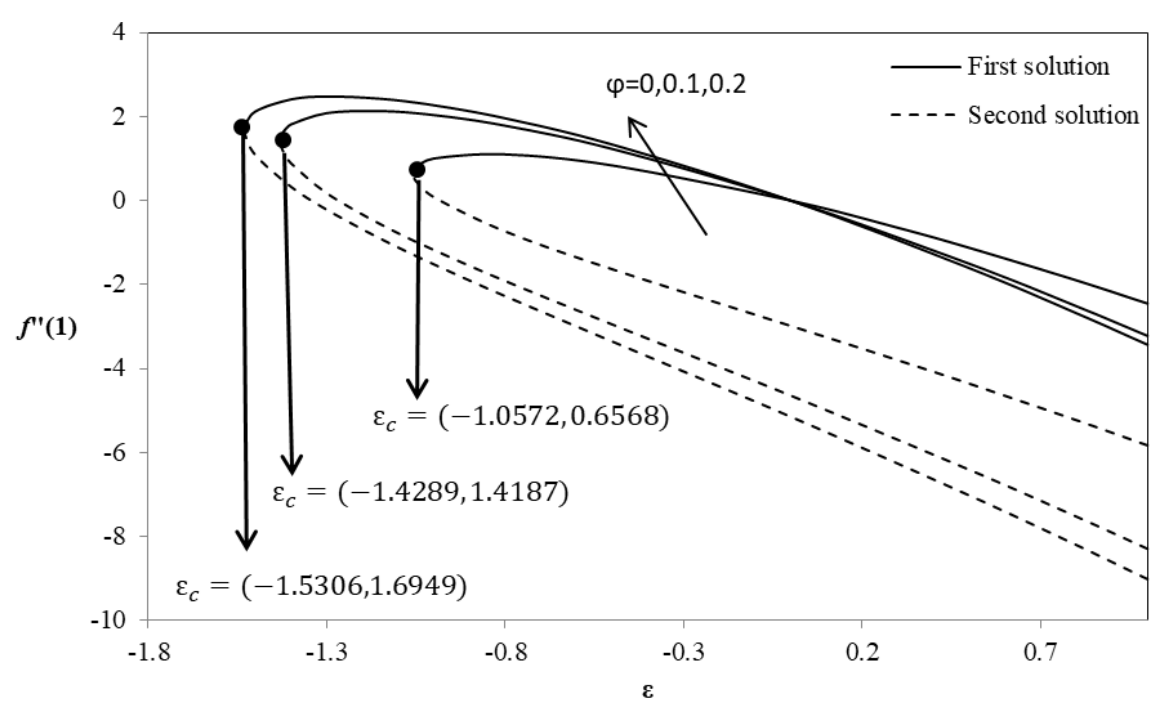

Fig. 4. Variations of $f^{\prime \prime}(1)$ with $\varepsilon$ for different values of $\varphi$ when $s=1$ and $A=-1$

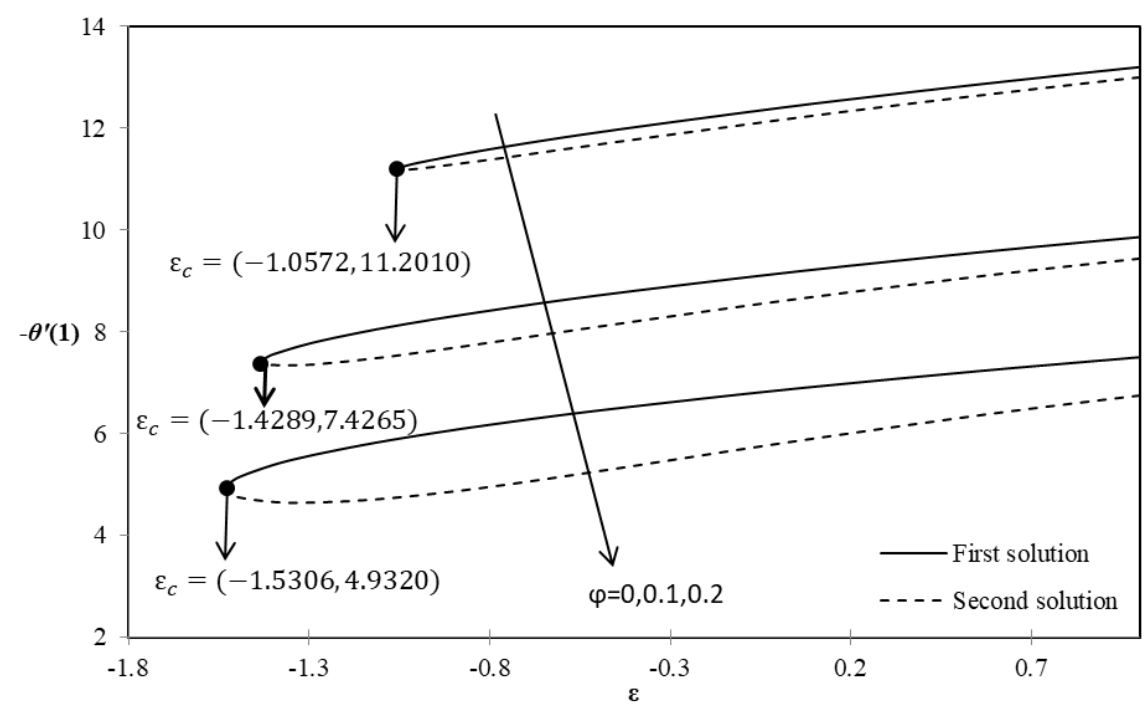

Fig. 5. Variations of $-\theta^{\prime}(1)$ with $\varepsilon$ for different values of $\varphi$ when $s=1$ and $A=-1$

Table 2 is tabulated to present the smallest eigenvalues, which determine the stability of the solutions obtained for different $\varphi$. A solution is stable and physically realizable if the eigenvalues are positive and unstable if the values are negative. Based on Table 2, it is found that the smallest eigenvalues for the first solution are positive, which indicates that it is a stable and realizable solution but not for the second solution since it has negative eigenvalues. 


\section{Table 2}

The smallest eigenvalue $\gamma$ for different $\varphi$

\begin{tabular}{llll}
\hline$\varphi$ & $\varepsilon$ & $\gamma$ (First solution) & $\gamma$ (Second solution) \\
\hline 0 & -1.5072 & 0.1903 & -0.1718 \\
& -1.5071 & 0.1908 & -0.1738 \\
& -1.5070 & 0.1912 & -0.1752 \\
0.1 & -1.4288 & 0.2160 & -0.2312 \\
& -1.4287 & 0.2164 & -0.2336 \\
& -1.4280 & 0.2183 & -0.2428 \\
0.2 & -1.5307 & 0.2226 & -0.2394 \\
& -1.5305 & 0.2292 & -0.2470 \\
& -1.5300 & 0.2308 & -0.2552 \\
\hline
\end{tabular}

\section{Conclusion}

The unsteady boundary layer flow over a stretching/shrinking cylinder in Cu-water nanofluid was investigated using Tiwari and Das model. It was found that dual solutions can be found for both stretching/shrinking cases for unsteady boundary layer flow problems passed through the cylinder when the value of the unsteadiness parameter is negative $(A<0)$. Besides that, increasing $\mathrm{Cu}$ nanoparticle volume fraction, $\varphi$ in the water tended to delay the boundary layer separations, which lead to expanding the range of the solutions obtained. In addition, the velocity gradient at the surface increased when $\varphi$ increased, however, the temperature gradient was decreased for the same effect. The stability analysis showed that the first solution was the stable solution and physically realizable.

\section{Acknowledgment}

We are very grateful to the experts for their appropriate and constructive suggestions to improve this paper. This work was supported by Fundamental Research Grant Scheme (FRGS/1/2017/STG06/UiTM/02/9) from the Ministry of Higher Education, Malaysia.

\section{References}

[1] Tie-Gang, Fang, Zhang Ji, Zhong Yong-Fang, and Tao Hua. "Unsteady viscous flow over an expanding stretching cylinder." Chinese Physics Letters 28, no. 12 (2011): 124707. https://doi.org/10.1088/0256-307X/28/12/124707

[2] Zaimi, WMKA Wan, Anuar Ishak, and Ioan Pop. "Unsteady viscous flow over a shrinking cylinder." Journal of King Saud University-Science 25, no. 2 (2013): 143-148. https://doi.org/10.1016/j.jksus.2012.11.005

[3] Marinca, Vasile, and Remus-Daniel Ene. "Dual approximate solutions of the unsteady viscous flow over a shrinking cylinder with optimal Homotopy Asymptotic Method." Advances in Mathematical Physics 2014 (2014): 1-11. https://doi.org/10.1155/2014/417643

[4] Zaimi, Khairy, Anuar Ishak, and Ioan Pop. "Unsteady flow due to a contracting cylinder in a nanofluid using Buongiorno's model." International Journal of Heat and Mass Transfer 68 (2014): 509-513. https://doi.org/10.1016/i.ijheatmasstransfer.2013.09.047

[5] Mahdy, A., and A. Chamkha. "Heat transfer and fluid flow of a non-Newtonian nanofluid over an unsteady contracting cylinder employing Buongiorno's model." International Journal of Numerical Methods for Heat \& Fluid Flow 25, no. 4 (2015): 703-723. https://doi.org/10.1108/HFF-04-2014-0093

[6] Abbas, Z., S. Rasool, and M. M. Rashidi. "Heat transfer analysis due to an unsteady stretching/shrinking cylinder with partial slip condition and suction." Ain Shams Engineering Journal 6, no. 3 (2015): 939-945. https://doi.org/10.1016/j.asej.2015.01.004

[7] Azam, M., M. Khan, and A. S. Alshomrani. "Unsteady radiative stagnation point flow of MHD Carreau nanofluid over expanding/contracting cylinder." International Journal of Mechanical Sciences 130 (2017): 64-73. https://doi.org/10.1016/j.ijmecsci.2017.06.010

[8] Khan, Ansab Azam, Khairy Zaimi, and Teh Yuan Ying. "Stagnation point flow of Williamson nanofluid towards a permeable stretching/shrinking sheet with a partial slip." CFD Letters 12, no. 6 (2020): 39-56. https://doi.org/10.37934/cfdl.12.6.3956 
[9] Awaludin, Izyan Syazana, Rokiah Ahmad, and Anuar Ishak. "On the stability of the flow over a shrinking cylinder with prescribed surface heat flux." Propulsion and Power Research 9, no. 2 (2020): 181-187. https://doi.org/10.1016/j.jppr.2020.03.001

[10] Fang, Tie-gang. "New unsteady boundary layers over a long thin cylinder." Meccanica 50, no. 12 (2015): $2907-2918$. https://doi.org/10.1007/s11012-015-0177-1

[11] Yashkun, Ubaidullah, Fatinnabila Kamal, Khairy Zaimi, Nor Ashikin Abu Bakar, and Norshaza Atika Saidin. "Stability analysis on stagnation-point flow and heat transfer towards a permeable stretching/shrinking sheet with heat source in a Casson fluid." CFD Letters 12, no. 6 (2020): 1-15. https://doi.org/10.37934/cfdl.12.6.115

[12] Parvin, Shahanaz, Siti Suzilliana Putri Mohamed Isa, Norihan Md Arifin, and Fadzilah Md Ali. "Dual numerical solutions on mixed convection Casson fluid flow due to the effect of the rate of extending and compressing sheetStability analysis." CFD Letters 12, no. 8 (2020): 76-84. https://doi.org/10.37934/cfdl.12.8.7684

[13] Usman, Auwalu Hamisu, Sadiya Ali Rano, Usa Wannasingha Humphries, and Poom Kumam. "Activity of Viscoelastic Nanofluid Film Sprayed on a Stretching Cylinder with Arrhenius Activation Energy and Entropy Generation. "Journal of Advanced Research in Micro and Nano Engineering 3, no. 1 (2020): 12-24.

[14] Rashid, Umair, Haiyi Liang, Hijaz Ahmad, Muhammad Abbas, Azhar lqbal, and Y. S. Hamed. "Study of (Ag and $\mathrm{TiO} 2$ )/water nanoparticles shape effect on heat transfer and hybrid nanofluid flow toward stretching shrinking horizontal cylinder. "Results in Physics 21 (2021): 103812. https://doi.org/10.1016/i.rinp.2020.103812

[15] Elsaid, Essam M., and Mohamed S. Abdel-wahed. "Impact of hybrid nanofluid coolant on the boundary layer behavior over a moving cylinder: Numerical case study." Case Studies in Thermal Engineering 25 (2021): 100951. https://doi.org/10.1016/j.csite.2021.100951

[16] Khan, Umair, A. Zaib, and A. Ishak. "Non-similarity solutions of radiative stagnation point flow of a hybrid nanofluid through a yawed cylinder with mixed convection." Alexandria Engineering Journal 60 (2021): 5297-5309. https://doi.org/10.1016/j.aej.2021.04.057

[17] Tiwari, Raj Kamal, and Manab Kumar Das. "Heat transfer augmentation in a two-sided lid-driven differentially heated square cavity utilizing nanofluids." International Journal of Heat and Mass Transfer 50, no. 9-10 (2007): 2002-2018. https://doi.org/10.1016/i.ijheatmasstransfer.2006.09.034

[18] Weidman, P. D., D.G. Kubitschek, and A. M. J. Davis. "The effect of transpiration on self-similar boundary layer flow over moving surfaces." International Journal of Engineering Science 44, no. 11-12 (2006): $730-737$. https://doi.org/10.1016/j.ijengsci.2006.04.005

[19] Ismail, Nurul Syuhada, Norihan Md Arifin, Roslinda Nazar, and Norfifah Bachok. "Stability analysis of unsteady MHD stagnation point flow and heat transfer over a shrinking sheet in the presence of viscous dissipation." Chinese Journal of Physics 57 (2019): 116-126. https://doi.org/10.1016/i.ciph.2018.12.005

[20] Oztop, Hakan F., and Eiyad Abu-Nada. "Numerical study of natural convection in partially heated rectangular enclosures filled with nanofluids." International Journal of Heat and Fluid Flow 29, no. 5 (2008): 1326-1336. https://doi.org/10.1016/j.ijheatfluidflow.2008.04.009 